\title{
Delayed surgery in patients with acute type $A$ aortic dissection who are receiving novel oral anticoagulants
}

Raphael Hamad, BSc, Gilles Amr, MD, MSc, and Philippe Demers, MD, MSc, FRCSC, Montréal, Québec, Canada

From the Department of Cardiac Surgery, Montreal Heart Institute-Université de Montréal, Montréal, Québec, Canada.

Disclosures: Authors have nothing to disclose with regard to commercial support.

Received for publication May 13, 2017; revisions received June 27, 2017; accepted for publication Aug 1, 2017 ; available ahead of print Sept 12, 2017

Address for reprints: Philippe Demers, MD, MSc, FRCSC, Montreal Heart Institute, 5000 Belanger St, Montreal, Quebec H1T 1C8, Canada (E-mail: philippe.demers@icm-mhi.org).

J Thorac Cardiovasc Surg 2018;155:e1-4

$0022-5223 / \$ 36.00$

Copyright (C) 2017 by The American Association for Thoracic Surgery

http://dx.doi.org/10.1016/j.jtcvs.2017.08.021

Video clip is available online.

Use of novel oral anticoagulants (NOACs) is increasing, but without a means of rapid and efficacious reversal, this can represent a disaster should urgent and invasive surgical care be required. Here we describe our overall management,
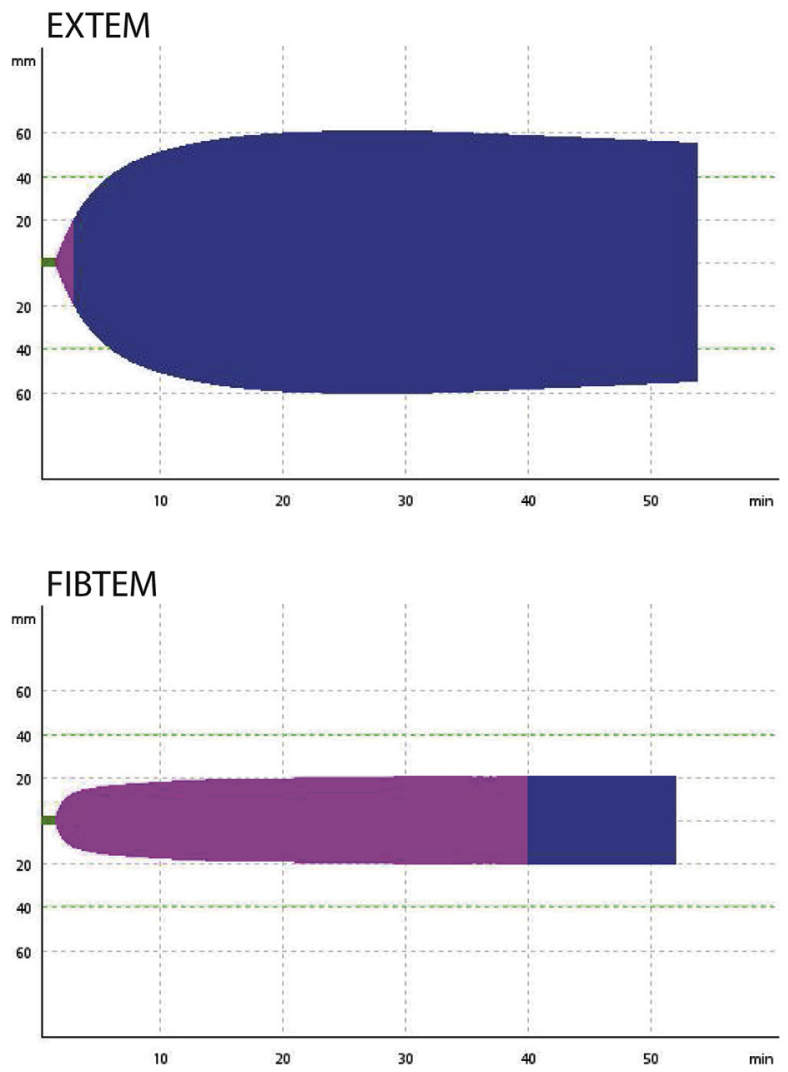

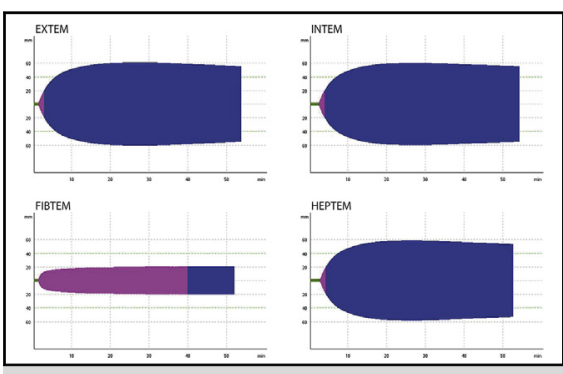

Normal coagulation per TEM test 60 hours postpresentation after receiving 1000 IU PCC.

\section{Central Message}

In managing acute type $\mathrm{A}$ ascending aortic dissection in patients receiving NOACs, risk of rupture weighs against risk of intractable bleeding. Delaying surgery should be considered in selected cases.

See Editorial Commentary page e5.
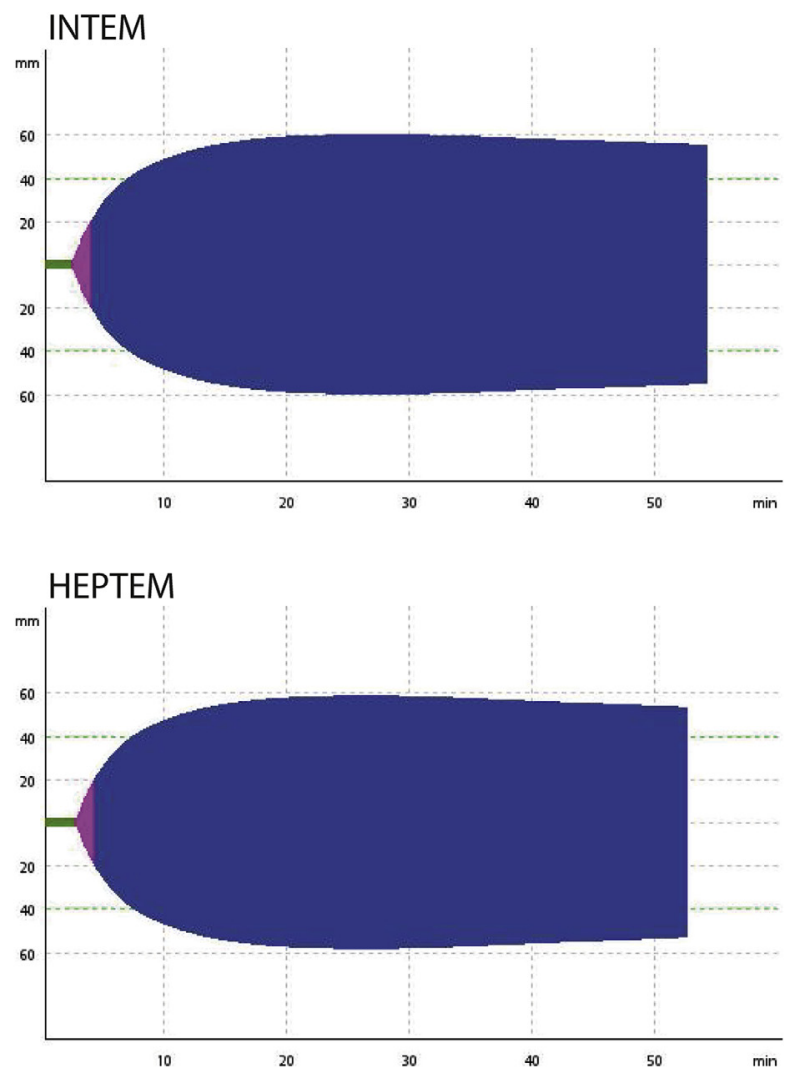

FIGURE 1. In patient 1, 60 hours after presentation and after receiving $1000 \mathrm{IU}$ of prothrombin complex concentrate, thromboelastometry testing showed normal coagulation. 
TABLE 1. Coagulation parameters on thromboelastometry testing

\begin{tabular}{|c|c|c|c|}
\hline & $18 \mathrm{~h}$ after onset & Incision & Closure \\
\hline Patient 1 & & $60 \mathrm{~h}$ & \\
\hline \multicolumn{4}{|l|}{ INTEM } \\
\hline $\mathrm{CT}(\mathrm{s})$ & & 140 & 167 \\
\hline CFT (s) & & 91 & $172 \uparrow$ \\
\hline$\alpha$ (degrees) & & 73 & 71 \\
\hline MA (mm) & & 60 & 48 \\
\hline \multicolumn{4}{|l|}{ EXTEM } \\
\hline $\mathrm{CT}(\mathrm{s})$ & & $97 \uparrow$ & $12 \downarrow$ \\
\hline CFT (s) & & 97 & 91 \\
\hline$\alpha$ (degrees) & & 74 & 73 \\
\hline MA (mm) & & 61 & 61 \\
\hline \multicolumn{4}{|l|}{ FIBTEM } \\
\hline $\mathrm{CT}(\mathrm{s})$ & & 75 & 97 \\
\hline CFT (s) & & 2312 & - \\
\hline$\alpha$ (degrees) & & 71 & 58 \\
\hline MA (mm) & & 20 & 16 \\
\hline \multicolumn{4}{|l|}{ HЕРТЕМ } \\
\hline CT (s) & & 159 & 225 \\
\hline CFT (s) & & 89 & 200 \\
\hline$\alpha$ (degrees) & & 73 & 64 \\
\hline MA (mm) & & 58 & 40 \\
\hline Patient 2 & & $40 \mathrm{~h}$ & \\
\hline \multicolumn{4}{|l|}{ INTEM } \\
\hline CT (s) & 170 & 180 & $1923 \uparrow$ \\
\hline CFT (s) & 103 & 81 & - \\
\hline$\alpha$ (degrees) & 71 & 75 & - \\
\hline MA (mm) & 59 & 62 & - \\
\hline \multicolumn{4}{|l|}{ EXTEM } \\
\hline $\mathrm{CT}(\mathrm{s})$ & 71 & 73 & $92 \uparrow$ \\
\hline CFT (s) & 105 & 92 & 114 \\
\hline$\alpha$ (degrees) & 70 & 72 & 71 \\
\hline MA (mm) & 61 & 63 & 59 \\
\hline \multicolumn{4}{|l|}{ FIBTEM } \\
\hline $\mathrm{CT}(\mathrm{s})$ & 64 & 65 & 95 \\
\hline CFT (s) & - & 1477 & - \\
\hline$\alpha$ (degrees) & 73 & 76 & 73 \\
\hline MA (mm) & 17 & 20 & 20 \\
\hline \multicolumn{4}{|l|}{ HЕРТЕМ } \\
\hline $\mathrm{CT}(\mathrm{s})$ & 164 & 168 & 186 \\
\hline CFT (s) & 97 & 82 & 94 \\
\hline$\alpha$ (degrees) & 71 & 76 & 75 \\
\hline MA (mm) & 60 & 61 & 60 \\
\hline
\end{tabular}

INTEM, Intrinsic rotational thromboelastometry; EXTEM, extrinsic rotational thromboelastometry; FIBTEM, fibrinogen rotational thromboelastometry; HEPTEM, heparin rotational thromboelastometry; $C T$, clotting time; $C F T$, clot formation time; $\alpha$, $\alpha$-angle; $M A$, maximum amplitude.

including delayed surgery, of 2 patients who each presented with acute Stanford type A aortic dissection while receiving NOACs (rivaroxaban and dabigatran).

\section{CLINICAL SUMMARIES}

\section{Patient 1}

An 87-year-old women came to a primary care hospital with retrosternal pain and syncope. She was being treated

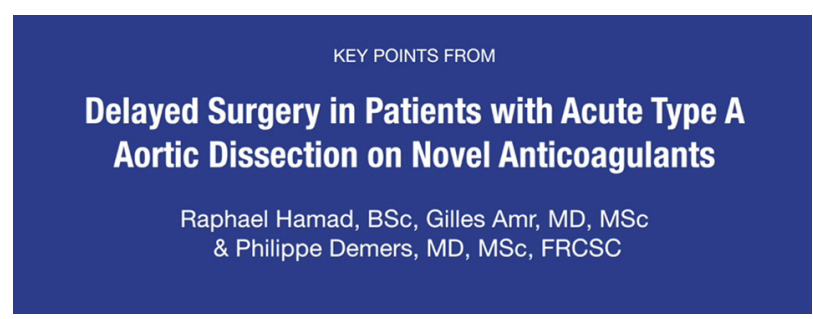

VIDEO 1. Key points on delayed operative repair and computed tomographic scan findings for patients 1 and 2. Video available at: http://www.jtcvsonline.org/article/S0022-5223(17)31778-6/fulltext.

with rivaroxaban at $15 \mathrm{mg}$ daily for paroxysmal atrial fibrillation, and her last dose had been at noon the same day. Angioscan showed an acute Stanford type A aortic dissection sparing the supra-aortic vessels and coronary arteries and only minimal hemopericardium. These findings are presented in Video 1. She was transferred to our facility with a nitroprusside sodium drip. At arrival, she was in hemodynamically stable condition and showed no signs of malperfusion. Labetalol was initiated to achieve a systolic blood pressure of at most $100 \mathrm{~mm} \mathrm{Hg}$. She received $1000 \mathrm{IU}$ of human prothrombin complex that same day. A control angioscan $24 \mathrm{~h}$ later showed no progression. Twice-daily anti-activated factor $\mathrm{X}$ assays calibrated for rivaroxaban were performed until negligible levels $(10 \mathrm{U} / \mathrm{mL})$ were reached $40 \mathrm{~h}$ after the last dose. Around 60 hours after initial presentation, the patient underwent an ascending aortic replacement with a hypothermic circulatory arrest of $15 \mathrm{mi}-$ nutes and a cardiopulmonary bypass time of 132 minutes. Preoperative thromboelastometry showed no deficit (Figure 1 and Table 1), but thrombocytopenia was corrected with 5 units of platelets. Perioperative blood loss was $1000 \mathrm{~mL}$. Chest tube output was minimal. There were no postoperative complications, and the patient was discharged on postoperative day 6 .

\section{Patient 2}

A 67-year-old man with known hypertension, hypothyroidism, dyslipidemia, and treatment with dabigatran at $150 \mathrm{mg}$ twice daily for chronic atrial fibrillation (last dose that morning) presented with acute type A aortic dissection. There was no aortic insufficiency, no hemopericardium, and no signs of malperfusion. Hemodynamics were stable. Nitroprusside, labetalol, and clonidine were initiated to achieve a systolic blood pressure of at most $100 \mathrm{~mm} \mathrm{Hg}$. The decision was taken with the family to delay the procedure and closely monitor the patient to minimize the risk of massive bleeding, weighing against the risk of rupture. The patient immediately received $5 \mathrm{~g}$ of idarucizumab. Forty hours later, the results of preoperative thromboelastometry (Table 1) were normal, and he underwent an ascending aorta and total arch replacement with a frozen elephant trunk 
TABLE 2. Review of published cases of acute type A aortic dissection in patients receiving novel oral anticoagulants

\begin{tabular}{|c|c|c|c|c|}
\hline \multirow[b]{2}{*}{ Report } & \multirow[b]{2}{*}{ NOAC } & \multicolumn{2}{|r|}{ Interventions } & \multirow[b]{2}{*}{ Survived } \\
\hline & & Preoperative & Perioperative/postoperative & \\
\hline \multicolumn{5}{|l|}{ Current report } \\
\hline Patient 1 & Rivaroxaban & PCC, $\sim 60$ h delay & Plt & Yes \\
\hline Patient 2 & Dabigatran & Praxbind, $\sim 40$ h delay & - & Yes \\
\hline Crapelli et al, ${ }^{2} 2016^{*}$ & Dabigatran & - & UF, PCC, rVIIa, Plt, FFP, Fg, PRBC & No \\
\hline Dumps et al, ${ }^{3} 2016$ & Apixaban & - & UF, PCC, Plt, FFP Fg, PRBC & No \\
\hline Henderson et al, ${ }^{4} 2016$ & Dabigatran & Idarucizumab & - & No \\
\hline Marchetti et al, ${ }^{7} 2016$ & Dabigatran & HD, FEIBA & - & Yes \\
\hline Béné et $\mathrm{al},{ }^{1} 2015$ & Rivaroxaban & PCC & - & No \\
\hline Ashikhmina et al, ${ }^{8} 2014$ & Dabigatran & - & UF, PCC, FEIBA, ACA & Yes \\
\hline Williamson et al, 2014 & Rivaroxaban & - & PCC, FEIBA, Plt, FFP, Cryo, PRBC & Yes \\
\hline Stein et al,,$^{5} 2014$ & Dabigatran & - & HD, PCC, rFVIIa, FVIII/vWF, FXIII, Plt, FFP, Fg, PRBC & No \\
\hline Mastrobuoni et al, ${ }^{9} 2012^{*}$ & Dabigatran & - & PCC, rFVIIa, FFP, Cryo & Yes \\
\hline
\end{tabular}

procedure with 28-mm Dacron polyester fabric grafts and a Gore TAG $31 \times 15 \mathrm{~mm}$ graft (W. L. Gore \& Associates; Flagstaff, Ariz). Arrest time was 14 minutes, and cardiopulmonary bypass time was 108 minutes. Blood loss was $390 \mathrm{~mL}$. Chest tube outputs were $180 \mathrm{~mL}$ in the first 8 hours and $290 \mathrm{~mL}$ in the first day. Notably, the patient received no blood products or coagulation factors. The postoperative course was uneventful, and the patient was discharged on postoperative day 7 .

\section{DISCUSSION}

Prevalence of use of NOACs, such as rivaroxaban and dabigatran, is increasing because they present many advantages relative vitamin $\mathrm{K}$ antagonists; however, rapid reversal still poses concern. Acute Stanford type A aortic dissection carries a mortality risk of $1 \%$ per hour for the first hours when treated medically. We describe 2 cases successfully managed by delaying surgery between 40 and 60 hours. Both patients were fortunate to have stable hemodynamics, no malperfusion, and no rupture. This allowed them to receive adequate surgery with minimal amounts of blood products and coagulation factors.

There is little existing literature on aortic dissection in patients treated with NOACs (Table 2). One report describes a patient receiving rivaroxaban who died before surgery. ${ }^{1}$ Another 4 reports describe the patient surviving at the price

TABLE 3. Mode of action, pharmacokinetic data, and monitoring for common novel oral anticoagulants

\begin{tabular}{lccc}
\hline & Dabigatran & Apixaban & Rivaroxaban \\
\hline Mode of action & Direct inhibition of thrombin & Direct inhibition of FXa & Direct inhibition of FXa \\
$\mathrm{T}_{\max }(\mathrm{h})$ & 1 & $3-4$ & $2-4$ \\
$\begin{array}{l}\text { Elimination } \\
\text { Mode }\end{array}$ & Renal & Renal & Renal \\
Unchanged & $80 \%$ & $27 \%$ & $36 \%$ \\
Elimination & $12-17$ & 12 & $11-13$ \\
$\quad$ half-life (h) & Ecarin-based assays in & & Calibrated anti-FXa, does not rule \\
Best monitoring & therapeutic range; TT to rule & out residual levels & out residual levels \\
& out residual levels & & INR/PT sensitive in therapeutic range, \\
insensitive to rule out residual levels; & APTT insensitive.
\end{tabular}

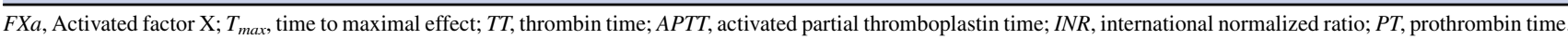


of significant transfusions, whereas 4 others describe the patient dying from intractable coagulopathy despite receiving massive amounts of blood products, coagulation factors, and, in 1 case, idarucizumab. ${ }^{2-9}$

There is no consensus regarding the optimal management of these patients. The persistent risk of rupture must be weighed against the risk of intractable bleeding and multiple transfusions. If the patient is in hemodynamically and clinically stable condition, with no signs of malperfusion, we suggest that it is reasonable to wait under intensive surveillance until coagulopathy has resolved. The timing of last NOAC dose is important in evaluating the bleeding risk. Coagulation status must be assessed frequently during the waiting interval. Calibrated anti-activated factor $\mathrm{X}$ assays are most sensitive to exclude therapeutic levels of apixaban or rivaroxaban, but they remain insensitive in the subtherapeutic range. In addition, these tests are not widely available. Thrombin time is most sensitive to exclude residual dabigatran levels. Prothrombin time, international normalized ration, and activated partial thromboplastin time are insensitive in this range for all three compounds ${ }^{10}$ (Table 3). If the patient has been treated with dabigatran and is in hemodynamically stable condition, continuous hemodialysis may be used to decrease serum concentration, although a rebound effect may be seen because of compartment redistribution. The most appropriate period of delay and the acceptable level of residual anticoagulation remain unknown. This paradigm should be confirmed in further studies.

\section{References}

1. Béné J, Auffray JL, Buffet M, Caron J, Gautier S. Aortic dissection during rivaroxaban therapy: a challenging care. Acta Anaesthesiol Scand. 2015;59:268.

2. Crapelli GB, Bianchi P, Isgrò G, Biondi A, de Vincentiis C, Ranucci M. A case of fatal bleeding following emergency surgery on an ascending aorta intramural hematoma in a patient taking dabigatran. J Cardiothorac Vasc Anesth. 2016;30: 1027-31.

3. Dumps C, Halbeck E, Schimpf J, Forst H. [Perioperative coagulation management during ascending aorta replacement on apixaban]. German. Anaesthesist. 2016;65:595-600.

4. Henderson RS Jr, Deshpande S, Williams B, Taylor BS, Tanaka KA. Idarucizumab for dabigatran reversal in emergency type-A aortic dissection. J Cardiothorac Vasc Anesth. May 13, 2016 [Epub ahead of print].

5. Stein P, Bosshart M, Brand B, Schlicker A, Spahn DR, Bettex D. Dabigatran anticoagulation and Stanford type A aortic dissection: lethal coincidence: case report with literature review. Acta Anaesthesiol Scand. 2014;58:630-7.

6. Williamson LD, Maxwell E, Silvers AJ, Marasco SF. Dabigatran anticoagulation and Stanford type A aortic dissection: not always a lethal coincidence? Acta Anaesthesiol Scand. 2014;58:1160-1.

7. Marchetti G, Giuliani E, Urbinati S, Barbieri A. Dabigatran anticoagulation and Stanford type A aortic dissection: not a lethal coincidence. Acta Anaesthesiol Scand. 2016;60:544.

8. Ashikhmina E, Tomasello N, Connors JM, Johana J, Davidson M, Mizuguchi KA. Type A aortic dissection in a patient on dabigatran: hemostasis post circulatory arrest. Ann Thorac Surg. 2014;98:2215-6.

9. Mastrobuoni S, Robblee JA, Boodhwani M. Spontaneous ascending aortic intramural haematoma in a patient on dabigatran. Interact Cardiovasc Thorac Surg. 2012;15:299-300

10. Lippi G, Favaloro EJ. Recent guidelines and recommendations for laboratory assessment of the direct oral anticoagulants (DOACs): is there consensus? Clin Chem Lab Med. 2015;53:185-97. 